\title{
EFEITOS DE DIFERENTES NUTRIENTES NA ESTRUTURA DO BIOFILME DENTAL FORMADO IN SITU E IN VITRO POR Streptococcus mutans
}

Aline Okamoto YOSHIZUMI, Danielle Gomes Lopes LIECHOCKI, Giulia Yuriko TANAKA, Cecília Fabiana da Gama FERREIRA, Elaine Machado BENELLI

A película adquirida favorece a adesão de microrganismos ao dente, contribuindo para formação do biofilme. O desequilíbrio entre biofilme/hospedeiro, devido alterações de $\mathrm{pH}$, dieta, fluxo e componentes salivares, favorece o desenvolvimento de doenças bucais, como cáries. Streptococcus mutans é considerado o principal agente etiológico da cárie devido sua capacidade de adesão, acidogenicidade e indução de mecanismo de tolerância a ácidos. Análises estrutural e bioquímica do biofilme formado por S. mutans em diferentes condições nutricionais contribuirão para entendimento de seu mecanismo de virulência. Neste estudo, biofilmes dentais formados in situ e in vitro sob diferentes fontes nutricionais foram caracterizados por Microscopia de Força Atômica. Nos experimentos in situ, voluntários utilizaram por 14 dias um dispositivo intra-oral contendo blocos de esmalte humano, tratados 8x/dia com soluções de nutrientes. Nos estudos in vitro, blocos de esmalte bovinos foram incubados por $24 \mathrm{~h}$ com culturas de S. mutans. Resultados mostraram que biofilmes formados in vitro e in situ em presença de sacarose e glucose são morfologicamente semelhantes. Biofilmes formados in situ em presença de amônia e/ou sacarose são morfologicamente semelhantes entre si, mas diferentes dos formados em presença apenas de sacarose. Estes resultados sugerem que a estrutura e morfologia do biofilme variam dependendo dos nutrientes. 